
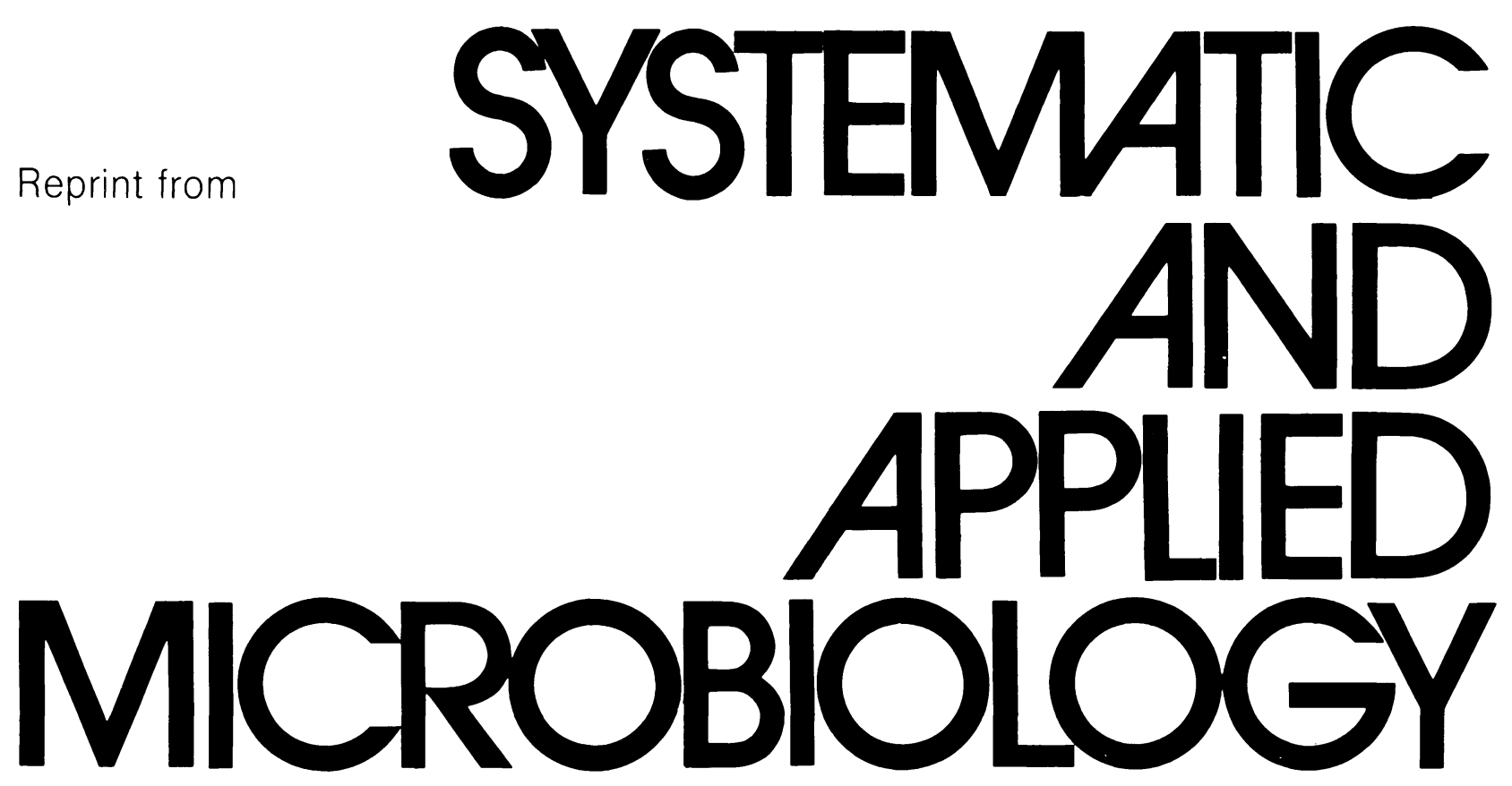

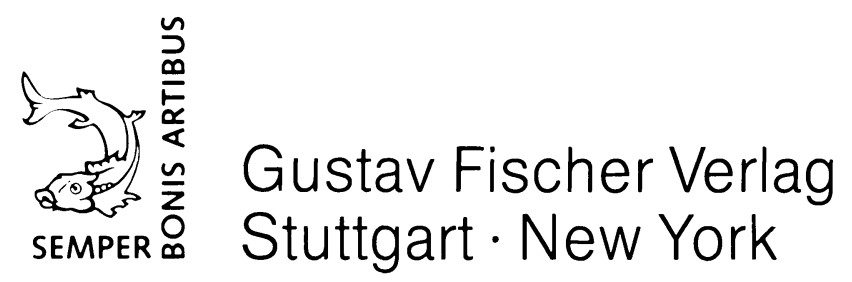




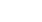


tenax: Sequence of the $16 \mathrm{~S}$ rRNA gene. System. Appl. Microbiol. 6, 164-170 (1985)

$L i$, W.-H., Graur, D.: Fundamentals of molecular evolution, Sunderland, Sinauer Association. 1991

Liao, D., Dennis, P. P.: The organization and expression of essential transcription translation component genes in the extremely thermophilic eubacterium Thermotoga maritima. J. Biol. Chem. 267, 22787-22797 (1992)

Lisitsyn, N. A., Monastryrskaya, G. S., Sverdlov, E. D.: Genes coding for polymerase $\beta$ subunit in bacteria. Eur. J. Biochem. 177, 363-369 (1988)

Obme, M., Tanaka, M., Chunwongse, J., Shinozaki, K., Sugiura, M.: A tobacco chloroplast DNA sequence possibly coding for a polypeptide similar to $E$. coli polymerase beta-subunit. FEBS Lett. 200, 87-90 (1986)

Obyama, K., Fukuzawa, H., Kohchi, T., Shirai, H., Sano, T., Sano, S., Umesono, K., Shiki, Y., Takeuchi, M., Chang, Z., Aota, S., Inokuchi, H., Ozeki, H.: Chloroplast gene organization deduced from complete sequence of liverwort Marchantia polymorpha chloroplast DNA. Nature 322, 572-574 (1986)

Olsen, G. J., Woese, C. R.: Ribosomal RNA: a key to phylogeny. The FASEB J. 7, 113-123 (1993)

Ovchinnikov, Y. A., Monastryskaya, G. S., Gubanov, V. V., Gureyev, S. O., Chertov, O. U., Modjanov, N. N., Grinkevich, V. A., Markova, I. A., Marchenkov, T. V., Polovnikova, I. N., Lipkin, V. M., Svederlov, E. D.: The primary structure of Escherichia coli RNA polymerase: Nucleotide sequence of the rpoB gene and amino acid sequence of the $\beta$-subunit. Eur. J. Biochem. 116, 621-629 (1981)

Ovchinnikov, Y. A., Monastryskaya, G. S., Gubanov, V. V., Gureyev, S. O., Salomatina, I. S., Shuvaea, T. M., Lipkin, V. M., Svederlov, E. D.: The primary structure of E. coli RNA polymerase. Nucleotide sequence of the rpoC gene and amino acid sequence of the $\beta^{\prime}$-subunit. Nucleic Acids Res. 10, 4035-4044 (1982)

Palm, P., Arnold-Ammer, I., Lechner, K., Zillig, W.: Nucleotide sequence of the RNA polymerase operon from Methanococcus vannielii. EMBL-GenBank data base, Accession No. X73293 (1993)

Pühler, G., Lottspeich, F., Zillig, W.: Organization and nucleotide sequence of the genes encoding the large subunits $A, B$ and $\mathrm{C}$ of the DNA-dependent RNA polymerase of the archaebacterium Sulfolobus acidocaldarius. Nucleic Acids Res. 17, 4517-4534 (1989)

Ree, H. K., Cao, K., Thurlow, D. L., Zimmermann, R. A.: The structure and organization of the $16 \mathrm{~S}$ ribosomal RNA gene from the archaebacterium Thermoplasma acidophilum. Can. J. Microbiol. 35, 124-133 (1989)

Saitou, N.: Property and efficiency of the maximum likelihood method for molecular phylogeny. J. Mol. Evol. 27, 261-273 (1988)

Seifarth, W., Petersen, G., Kontermann, R., Riva, M., Huet, J., Bautz, E. K. F.: Identification of the gene coding for the second-largest subunits of RNA polymerases I and III of Drosophila melanogaster. Mol. Gen. Genet. 228, 424-432 (1991)
Shinozaki, K., Ohme, M., Tanaka, M., Wakasugi, T., Hayashida, N., Matsubayashi, T., Zaita, N., Chunwongse, J., Obokata, J., Yamagushi-Shinozaki, K., Ohto, C., Torazawa, K., Meng, B. Y., Sugita, M., Deno, H., Kamogashira, T., Yamada, K., Kushuda, J., Takaiwa, F., Kato, A., Tohdoh, N., Shimada, H., Sugiura, M.: The complete nucleotide sequence of the tobacco chloroplast genome: Its gene organization and expression. EMBO J. 5, 2043-2049 (1986)

Stetter, K. O.: Life at the upper temperature border, pp. 195-219. In: Frontiers of life (J. and K. Tran Thanh Van, J. C. Mounolou, J. Schneider, C. McKay, eds.), Edition Frontieres, Singapore, Fong \& Sons Printers 1992

Sweetser, D., Nonet, M., Young, R. A.: Prokaryotic and eukaryotic RNA polymerases have homologous core subunits. Proc. Natl. Acad. Sci. USA 84, 1192-1196 (1987)

Swofford, D. L.: PAUP 3.0 user's manual. Illinois Natural History Survey, Champaign, Illinois, USA (1989)

Swofford, D. L., Olsen, G. J.: Phylogeny reconstruction, pp. 411-501. In: Molecular systematics (D. M. Hillis, C. Moritz, eds.) Sunderland, Sinauer Associates 1990

Woese, C. R., Olsen, G. J.: Archaeal phylogeny: Perspectives on the urkingdoms. System. Appl. Microbiol. 7, 161-177 (1986)

Woese, C. R.: Bacterial evolution. Microbiol. Rev. 51, 221-271 (1987)

Woese, C. R., Kandler, O., Wheelis, M. L.: Towards a natural system of organisms: proposal for the domains Archaea, Bacteria, and Eucarya. Proc. Natl. Acad. Sci. USA 87, 4576-4579 (1990)

Woese, C. R., Achenbach, L., Rouviere, P., Mandelco, L.: Archaeal phylogeny: Reexamination of the phylogenetic positon of Archaeoglobus fulgidus in light of certain composition-induced artifacts. System. Appl. Microbiol. 14, 364-371 (1991)

Wolters, J., Erdmann, V. A.: Cladistic analysis of 5S rRNA and $16 \mathrm{~S}$ rRNA secondary and primary structure - the evolution of eukaryotes and their relation to archaebacteria. J. Mol. Evol. 24, 152-166 (1986)

Yano, R., Nomura, M.: Suppressor analysis of temperature-sensitive mutations of the largest subunit of RNA polymerase I in Saccharomyces cerevisiae: A suppressor gene encodes the second-largest subunit of RNA polymerase I. Mol. Cell. Biol. 11, 754-764 (1991)

Yepiz-Plascencia, G. M., Radebaugh, C. A., Hallick, R. B.: The Euglena gracilis chloroplast rpoB gene. Novel gene organization and transcription of the RNA polymerase subunit operon. Nucl. Acids Res. 18, 1869-1878 (1990)

Zadeh, L. A.: Fuzzy sets. Information and control 8, 338-353 (1965)

Zillig, W., Klenk, H.-P., Palm, P., Leffers, H., Pühler, G., Garrett, $R$. A.: Did eukaryotes originate by a fusion event? Endocytobiosis and Cell Res. 6, 1-25 (1989)

Zillig, W., Palm, P., Klenk, H.-P.: A model of the early evolution of organisms: The arisal of the three domains of life from the common ancestor, pp. 163-182. In: The origin and evolution of the cell (H. Hartman, K. Matsuno, eds.) Singapore, World Scientific Publishing Co. 1992 


\title{
Transcription Factors and Termination of Transcription in Methanococcus
}

\author{
MICHAEL THOMM*, WINFRIED HAUSNER, and CARINA HETHKE
}

Institut für Allgemeine Mikrobiologie, Universität Kiel, 24188 Kiel, Germany

Received August 23, 1993

\begin{abstract}
Summary
We have recently shown that specific transcription in cell extracts of Methanococcus thermolithotrophicus depends upon a transcription factor that was separated from the RNA polymerase by phosphocellulose chromatography. Here, we provide evidence for a second transcription factor. This factor copurified with RNA polymerase during initial chromatographic steps, but it was resolved as a distinct activity required for cell-free transcription after centrifugation in sucrose density gradients. The native molecular weight of this factor was estimated by gel filtration to be 56000 . After electrophoresis under denaturing conditions, a $28 \mathrm{kDa}$ polypeptide was correlated with factor activity. Thus, the native transcription factor appeared to be a dimer composed of two polypeptides of identical molecular mass.

Oligo-dT sequences at the $3^{\prime}$-end of a tRNA ${ }^{\text {Val }}$ gene and internal sequences of this tRNA were modified by DNA deletions in order to investigate the nature of archaeal transcription terminators. Deletion of two residues of the decameric sequence 5'-TTTTAATTTT-3' reduced termination efficiency to about 27 percent of wild-type levels. Deletion of two additional residues from the 3 '-end completely abolished terminator function. Deletions in the DNA region encoding the TUC stem and loop of tRNA also significantly reduced termination efficiency. In addition a Rho-independent terminator of Escherichia coli perfectly replaced the decameric Methanococcus terminator sequence. These findings suggested that transcription termination sequences in archaea are similar to the terminator sequences in bacteria.
\end{abstract}

Key words: Archaea - Transcription Factors - Terminator - RNA Polymerase

\section{Introduction}

The initiation of transcription in archaea depends upon transcription factors. In Methanococcus thermolithotrophicus, the RNA polymerase was resolved from a factor required for correct initiation and termination of transcription by phosphocellulose chromatography (Frey et al., 1990; Gohl et al., 1992). Within crenarchaeota, a factor required for initiation of transcription at rRNA promoters was identified by centrifugation of crude extract in sucrose density gradients (Hüdepobl et al., 1990). Both the Methanococcus and Sulfolobus derived cell-free transcription systems were capable of correct initiation at promoters from a variety of homologous and heterologous archaeal

\section{* Corresponding author}

Abbreviations: aTF, archaeal transcription factor; PC, phosphocellulose; SDS, sodium dodecyl sulfate genes, indicating a high degree of conservation of transcription signals among archaea at the functional level (Hüdepohl et al., 1991; Thomm et al., 1992; Koller et al., 1992).

When the Methanococcus transcription factor purified by PC chromatography was reconstituted with the purified RNA polymerase, no specific transcription occurred (Frey et al., 1990). Thus, additional factors appeared to be required for accurate transcription. We report here on the purification of a second archaeal transcription factor that copurifies with RNA polymerase during the initial chromatographic steps but can be separated from the enzyme by sedimentation through sucrose density gradients.

Both archaeal transcription systems were used for mutational analyses of archaeal promoter structures (Reiter et al., 1990; Hausner et al., 1991). The major conclusion inferred from these studies was that archaeal promoters 
consist of an AT-rich TATA box located at position -25 and an initiator element, ATGC. The initiator element was required for wild-type levels of transcription, but it could be replaced by sequences containing a pyrimidine/purine dinucleotide. The TATA box was the most important element in specifying the transcription start site and resembled both in structure and function the TATA box of eukaryotic class II promoters ( $X \boldsymbol{u}$ et al., 1991). Although the sequences necessary for cell-free initiation of transcription have been analyzed in some detail, very little information is available on transcription terminators of archaea. The 3'-flanking regions of archaeal genes contain oligo-dT sequences and structures resembling Rho-independent terminators of Escherichia coli (Wich et al., 1986; Brown et al., 1989). However, the actual function of these sequences in termination has not been demonstrated. In the present study we report on the mutational analysis of the terminator region of the tRNA ${ }^{\mathrm{Val}}$ gene of Methanococcus vannielii. Our findings provide evidence that both oligo$\mathrm{dT}$ and internal tRNA-encoding sequences contribute to terminator function.

\section{Materials and Methods}

Purification of plasmid DNA. Templates for cell-free transcription experiments were purified by repeated centrifugation in $\mathrm{CsCl}$ density gradients as described previously (Frey, et al., 1990).

Construction of templates. The plasmid pIC31/2 containing the tRNA ${ }^{\mathrm{Val}_{\text {-gene }}}$ of M. vannielii (Frey et al., 1990; Hausner et al., 1991) was used for the construction of various templates for cell-free transcription experiments. The single BstBI cleavage site at position +88 was used to delete parts of the tRNA-encoding DNA sequence of $\mathrm{pIC} 31 / 2.2 \mu \mathrm{g}$ of the linearized plasmid were treated with 10 units of nuclease $S 1$ for $30 \mathrm{~min}$ at $37^{\circ} \mathrm{C}$ in a volume of $20 \mu \mathrm{l} \mathrm{S1}$ buffer ( $50 \mathrm{mM}$ sodium acetate (pH 4.6), 280 $\mathrm{mM} \mathrm{NaCl}, 4.5 \mathrm{mM} \mathrm{ZnSO}_{4}$ ). The resulting fragments were ligated and transformed into E. coli JM 109. The resulting clones pIC31/ 4 and $\mathrm{pIC} 31 / 5$ contained deletions from +89 to +93 and +89 to +103 , respectively. To construct plasmid pIC31/6, three restriction fragments were purified. The 144 bp NsiI-HpaII fragment containing the $\mathrm{tRNA}^{\mathrm{val}}$ sequence from position -60 to +83 and the 57 bp HpaII-NruI fragment harboring the residual part from +95 to the 3 '-end of the tRNA gene were isolated from the plasmid pIC31/1 (Hausner et al., 1991). Both purified fragments were ligated with a PstI (compatible to NsiI)-NruI fragment of the vector pIC-19H (Marsh et al., 1984). The deletion of the resulting clone pIC31/6 extended from +84 to +94 .

To investigate the 3 '-end of the terminator region of $\mathrm{pIC} 31 / 2$, a second terminator region was inserted downstream of the $\mathrm{tRNA}^{-\mathrm{Val}}$-gene. First, the $5^{\prime}$ protruding end of a $47 \mathrm{bp}$ Bst BIEcoRV fragment of pIC31/2 containing the terminator of the tRNA ${ }^{\mathrm{Val}}$-gene was filled in with the Klenow fragment of DNA polymerase I. This fragment was inserted into the NruI site of pIC 31/2 to obtain pIC31/12. This plasmid was used to construct the plasmids indicated below. To obtain a set of various deletion mutants of the 3 '-end of the first terminator region, synthetic oligonucleotides were used as adapters. To construct the reference clone pIC-31/36 containing two intact terminators, a 1921 bp SacI-AlwNI fragment of pIC31/12 containing the second terminator and a major part of the vector and a 919 bp AvallAlwNI fragment of pIC31/8 (Hausner et al., 1991) harboring the $\mathrm{tRNA}^{\mathrm{Val}}$-gene without the terminator were isolated. In a ligation
Table 1. Synthetic oligonucleotides used for construction of DNA deletion clones shown in Figs. 5 and 6; the construction of these clones is described under Materials and Methods

\begin{tabular}{|c|c|c|}
\hline Resulting plasmid & \multicolumn{2}{|l|}{ Oligonucleotides used } \\
\hline pIC-31/36A & \multirow{2}{*}{\multicolumn{2}{|c|}{$\begin{array}{l}5^{\prime} \text {-GTCCACTATTTTAATTTTGAGCT-3' } \\
3^{\prime}-\quad \text { GTGATAAAATTAAAAC }-5,\end{array}$}} \\
\hline $\mathrm{pIC}-31 / 36 \mathrm{~B}$ & & \\
\hline $\mathrm{pIC}-31 / 37 \mathrm{~A}$ & 5'-GTCCACTATTTTAATT & GAGCT-3' \\
\hline $\mathrm{pIC}-31 / 37 \mathrm{~B}$ & GTGATAAAATTAA & \\
\hline $\mathrm{pIC}-31 / 38 \mathrm{~A}$ & 5'-GTĊCACTATTTTAAT & GAGCT $-3^{\prime}$ \\
\hline $\mathrm{pIC}-31 / 38 \mathrm{~B}$ & GTGATAAAATTA & \\
\hline $\mathrm{pIC}-31 / 39 \mathrm{~A}$ & 5'-GTCCACTATTTTAA & GAGCT-3' \\
\hline pIC-31/39B & GTGATAAAATT & \\
\hline $\mathrm{pIC}-31 / 40 \mathrm{~A}$ & S'-GTCCACTATTTTA & GAGCT-3' \\
\hline $\mathrm{pIC}-31 / 40 \mathrm{~B}$ & GTGATAAAAT & \\
\hline $\mathrm{pIC}-31 / 41 \mathrm{~A}$ & 5'-GTCCACTATTTTT & GAGCT-3' \\
\hline pIC-31/41B & GTGATAAAAA & $-5^{\prime}$ \\
\hline pIC-31/42A & 5'-GTCCACTATTT & GAGCT-3' \\
\hline $\mathrm{pIC}-31 / 42 \mathrm{~B}$ & $3^{\prime}-\quad$ GTGATAAA & $-5^{\prime}$ \\
\hline
\end{tabular}

reaction, equivalent amounts of molecules of both fragments were incubated with the complementary oligonucleotides pIC31/ $36 \mathrm{~A}$ and pIC31/36B (Table I), which were used in a 100-fold excess. The ends of the hybridized oligonucleotides were compatible to the $5^{\prime}$ protruding end of the Avall cleavage site on one end and the $3^{\prime}$ extension of the SacI site on the other end. The clones $\mathrm{pIC} 31 / 37, \mathrm{pIC} 31 / 38, \mathrm{pIC} 31 / 39, \mathrm{pIC} 31 / 40, \mathrm{pIC} 31 / 41$ and $\mathrm{pIC} 31 /$ 42 (Fig. SA) were constructed in the same manner by using the corresponding oligonucleotides indicated in Table I. To construct a mutant in which the terminator region was replaced by a Rhoindependent terminator, a $190 \mathrm{bp} \mathrm{CfoI-HpaI} \mathrm{fragment} \mathrm{of} \mathrm{the}$ plasmid pPP15 containing the tRNA ${ }^{\text {Phe }}$-gene of E. coli (Caillet et al., 1985) was inserted into the vector pIC-20H (Marsh et al., 1984). This clone served as prerequisite for the construction of pIC31/23. For this clone, a 965 bp AlwNI-AvaII fragment containing a part of the vector and the tRNA ${ }^{\mathrm{Val}}$-gene without the terminator and a $1991 \mathrm{bp}$ AflII-AlwNI fragment containing the other part of the vector and the Rho-independent terminator were ligated and transformed into E. coli JM 109. The DNA sequences of all mutants were confirmed by dideoxy sequencing.

Purification of transcription factors and RNA polymerase. Components of the transcriptional machinery of $M$. thermolithotrophicus were purified from $10 \mathrm{~g}$ of cells (wet weight) as indicated in Fig. 1. To investigate the termination of transcription, extracts prepared from $5 \mathrm{~g}$ cells of $M$. vannielii were used. A $\mathrm{S}-100$ was applied to a $30 \mathrm{ml}$ bed-volume DEAE cellulose column equilibrated with TMK buffer [50 mM Tris $\mathrm{HCl}, \mathrm{pH} 7.9,10 \mathrm{mM}$ $\mathrm{MgCl}_{2}, 50 \mathrm{mM} \mathrm{KCl}, 20 \%$ glycerol (v/v)]. Bound protein was eluted with a linear gradient ( $50 \mathrm{mM}-1 \mathrm{M} \mathrm{KCl}$ in TMK buffer). Pooled fractions with RNA polymerase activity were diluted $1: 3$ with TMK buffer and applied to a Mono-Q FPLC column. RNA polymerase and aTFB were resolved by step-elution with $0.8 \mathrm{M}$ $\mathrm{KCl}$. aTFA from $M$. vannielii was purified by phosphocellulose chromatography of a S-100 as described previously (Frey et al., 1990).

Transcription assays. Nonspecific and specific transcription reactions using extracts of $M$. thermolithotrophicus were carried 
out as described previously (Thomm and Stetter, 1985; Frey et al., 1990). Cell-free transcription reactions reconstituted for analyses of termination of transcription from extracts of $M$. vannielii contained: $5 \mathrm{mM} \mathrm{MgCl}, 180 \mathrm{mM} \mathrm{KCl}, 40 \mathrm{mM}$ Tris $\mathrm{HCl}$ (pH 8.0), $0.05 \mathrm{mM} \mathrm{ZnSO}_{4}, 0.1 \mathrm{mM}$ EDTA, $2 \mu \mathrm{l}$ of the MONO$\mathrm{Q}$ fraction of RNA polymerase, $9 \mu \mathrm{l}$ of the PC fraction of aTFA, and $2 \mu \mathrm{g}$ of plasmid DNA linearized by hydrolysis with PvuII.

Analytical procedures. Polypeptides and labelled RNA products were identified by polyacrylamide gel electrophoresis as described previously (Thomm and Stetter, 1985; Frey et al., 1990). Silver staining of proteins was carried out using the procedure described by Heukeshoven and Dernick (1988).

\section{Results}

\section{Transcription factors in Methanococcus}

A procedure to separate three distinct components required for cell-free transcription of a tRNA ${ }^{\mathrm{Val}}$ gene of $M$. vannielii was developed (Fig. 1). One factor, aTFA or archaeal transcription factor A, identified previously by PC chromatography was further purified by Heparin-cellulose-chromatography. The Heparin-cellulose fraction of this factor was stable. Upon further purified, aTFA was rapidly inactivated. Hence, the fairly crude Heparin-fraction is the most purified preparation available at present.
When the PC fraction of RNA polymerase (Fig. 1) was purified via Heparin-cellulose and Mono Q-FPLC chromatography, the enzyme was still capable of specific transcription when reconstituted with aTFA (data not shown). However, upon sedimentation of the Mono-Q fraction through a sucrose density gradient a second transcription factor was identified (Fig. 2). The RNA polymerase, identified both by SDS PAGE (Fig. 2, lower part) and a nonspecific transcription assay (Fig. 2, top) was detected in fractions 16-22 of the gradient. This enzyme was unable to synthesize pre-tRNA efficiently (Fig. 3, lanes 2). Thus, a component necessary for cell-free transcription appeared to have been separated during centrifugation. To test this possibility, fractions from the upper part of the gradient that did not contain detectable RNA polymerase activity (Fig. 2), were added to cell-free transcription reactions. Analysis of the RNA products revealed that addition of fractions 6-10 of the gradient led to a dramatic increase of specific transcription (Fig. 3, Lanes 4-6). The presumed second transcription factor in these fractions was tentatively designated as aTFB. While only a few polypeptides were detected in fractions $6-10$ of the gradient by SDS PAGE and Coomassie Blue staining (Fig. 2), none could be correlated with factor activity. Therefore, further purification was performed by chromatography on Q-Sepharose

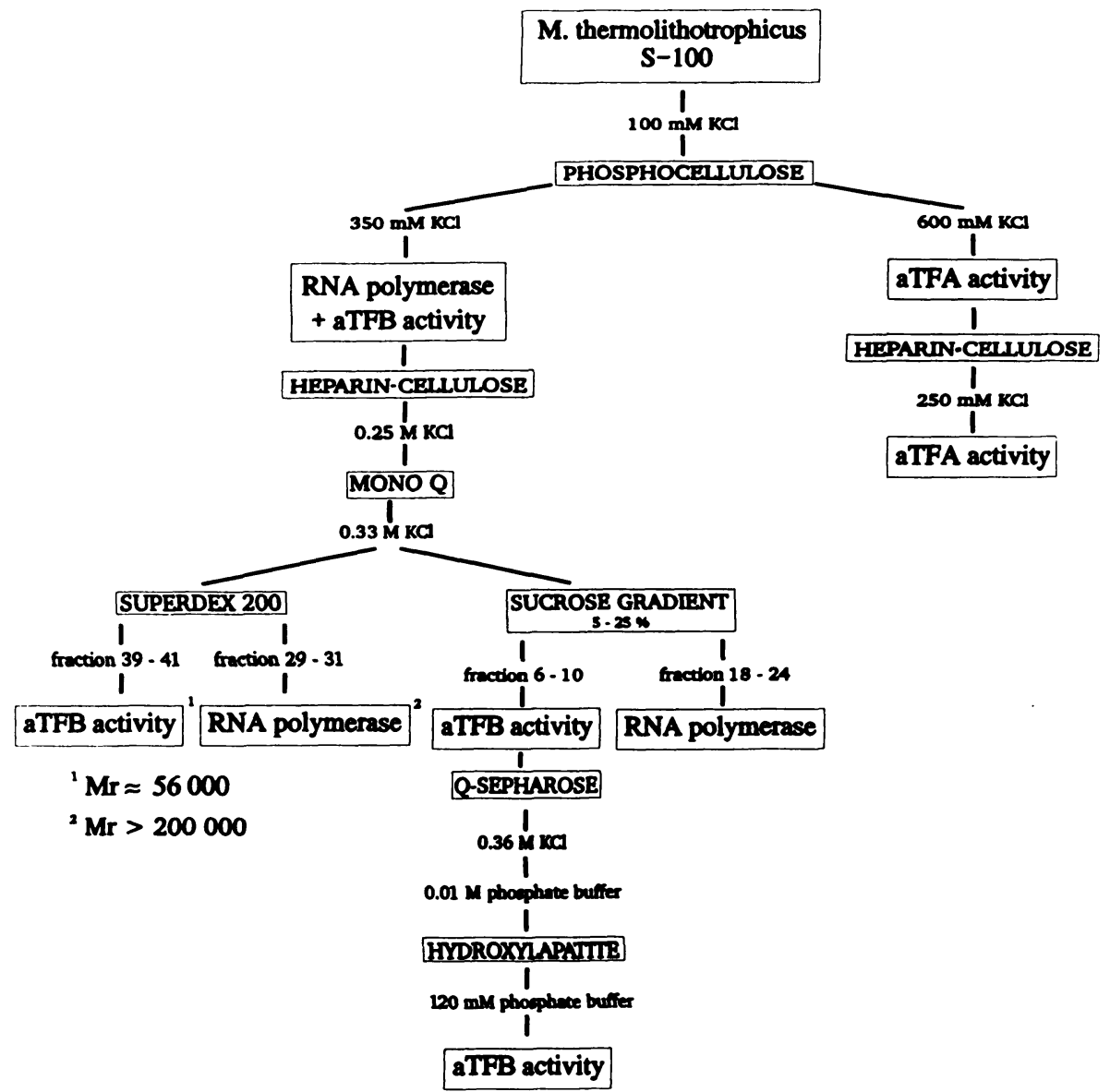

Fig. 1. Purification scheme for the isolation of RNA polymerase and enrichment of two transcription factors from M. thermolithotrophicus. 

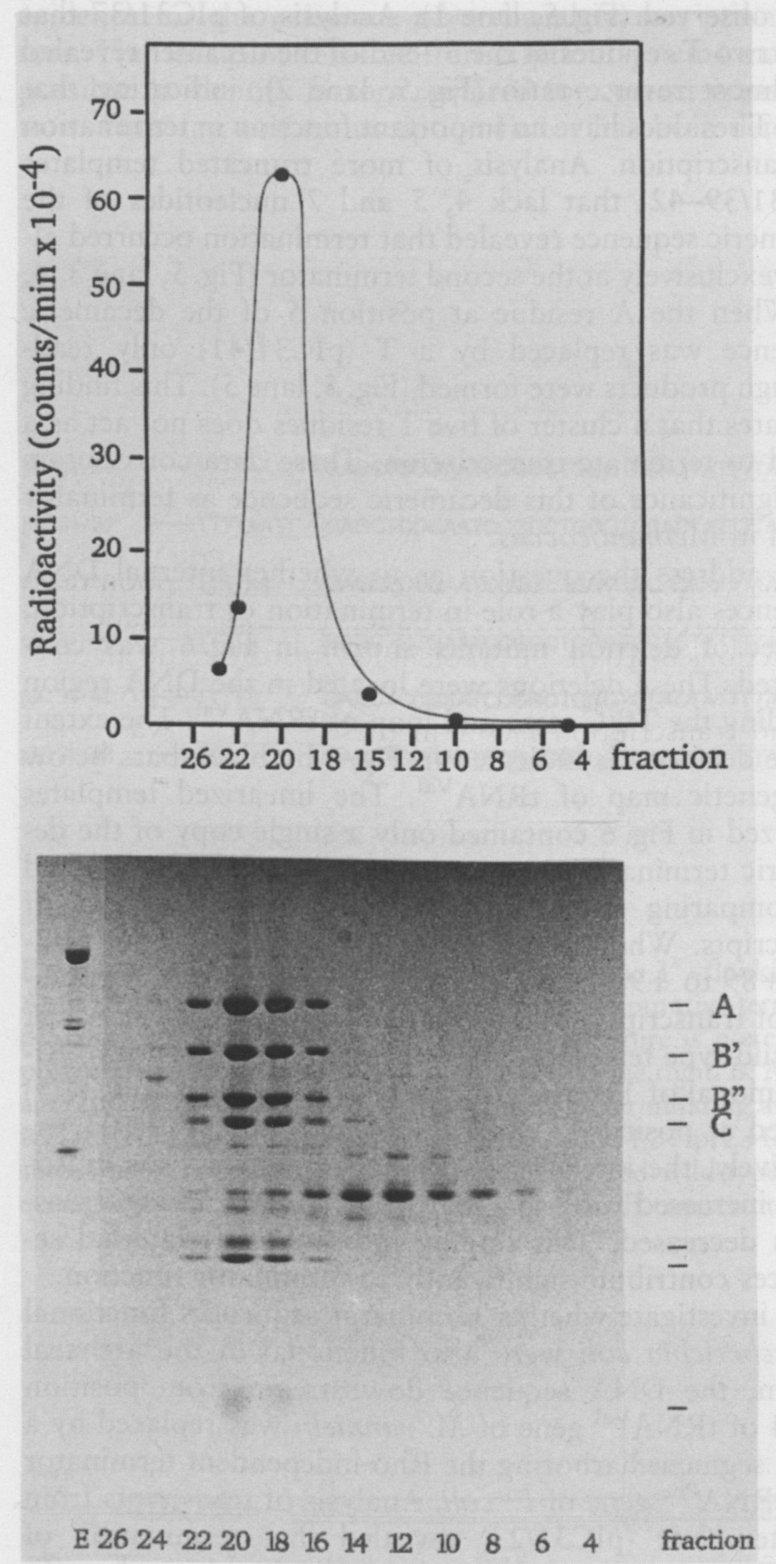

Fig. 2. Analysis of RNA polymerase and aTFB fractions purified by sedimentation through sucrose density gradients. Panel on top: RNA polymerase activity of fractions of the gradient determined in a nonspecific assay employing poly (d(AT)) as template. Lower panel: Analysis of fractions of the gradient by SDS PAGE. Polypeptides were stained with Coomassie Blue; 4 subunits of the RNA polymerase are indicated to the right with $A, B^{\prime}, B^{\prime \prime}, C$ according to the designations proposed previously (Schnabel et al., 1983; Thomm et al., 1986). E, RNA polymerase of E. coli is shown as a reference.

and hydroxylapatite (Fig. 1), and fractions containing aTFB activity were analyzed in silver-stained polyacrylamide gels. Fig. 4 shows an analysis of the fractions eluted from a hydroxylapatite column. aTFB activity eluted as a sharp peak in fractions $11-12$ of the gradient (top). While these fractions contained several polypeptides (Fig. 4, low- er part), the intensity of a single polypeptide (labelled by an arrow) was correlated with aTFB activity. Therefore, transcription factor activity most likely resided with this polypeptide. The molecular mass of aTFB estimated from analysis of its mobility during SDS PAGE was 28000 . Separation of aTFB and RNA polymerase was also achieved by Superdex 200 FPLC chromatography (Fig. 1; data not shown). The native molecular mass of aTFB estimated by elution from a calibrated Superdex column was 56000 . Since the native molecular mass of aTFB was twice that of the denatured polypeptide, the native aTFB appeared to be a dimer composed of two $28 \mathrm{kDa}$ polypeptides. A manuscript reporting complete purification of aTFB is in press (Hausner and Thomm, 1993).

\section{Studies on termination of transcription}

To identify the DNA sequences directing termination of transcription in an archaeon, the 3 '-end and internal regions of tRNA ${ }^{\mathrm{Val}}$ gene of M. vannielii were modified by DNA deletions. Termination at the decameric sequence $5^{\prime}-$ TTTTAATTTT-3' located at the 3 '-end of the gene encoding $\mathrm{tRNA}^{\mathrm{Val}}$, was compared to termination in mutants

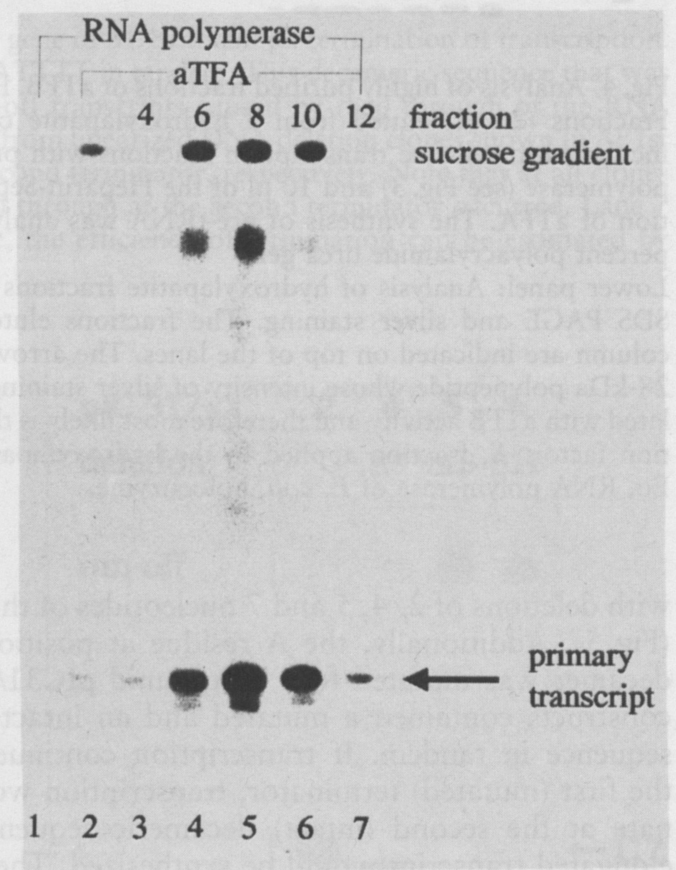

Fig. 3. Identification of a second transcription factor activity in M. thermolithotrophicus. Pooled RNA polymerase peak activity fractions of the sucrose gradient $(10 \mu \mathrm{l}$; fractions $17-21$ of Fig. 2$)$ were incubated in cell-free transcription reactions (Materials and Methods) with $10 \mu \mathrm{l}$ of the PC-fraction of aTFA in the presence (lane 3-7) and absence (lane 2) of fractions (5 $\mu \mathrm{l}$ ) of the upper part of the gradient. The particular fractions of the sucrose gradient used for this reconstitution experiment are indicated on top of the lanes. Lane 1, transcription reactions did contain neither aTFA nor aTFB (only RNA polymerase $=$ pol). The weak signals visible in lane 2 and 3 are caused by traces of aTFB contained in this particular PC fraction of aTFA. 


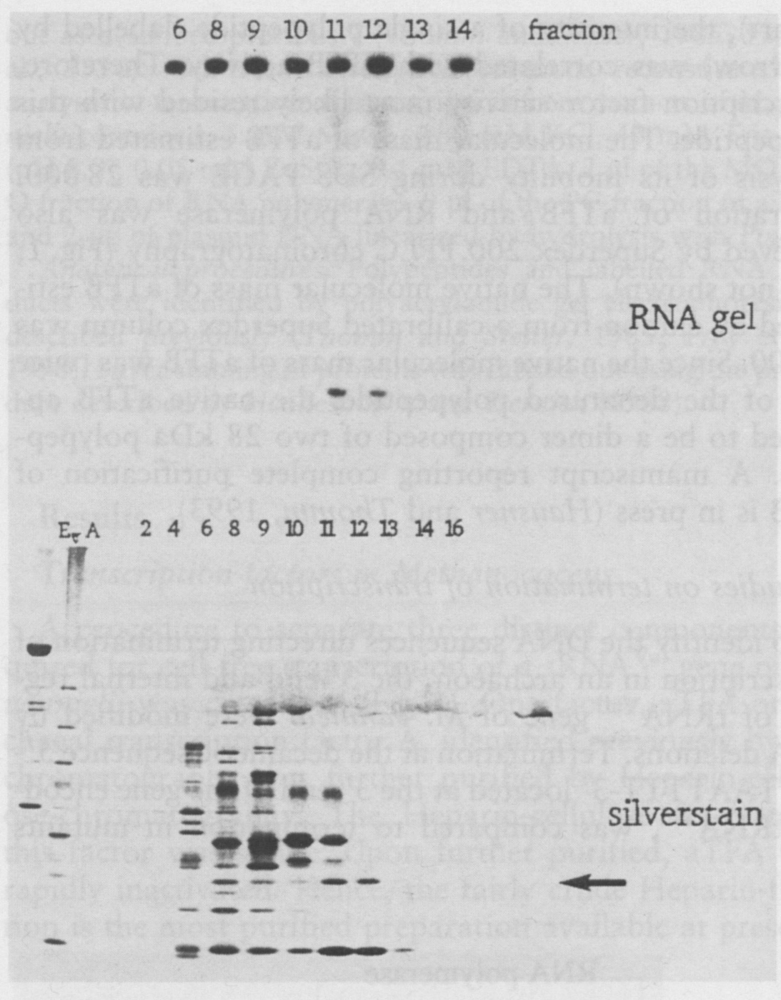

Fig. 4. Analysis of highly purified fractions of aTFB. Panel on top: Fractions $(20 \mu \mathrm{l})$ eluted from a hydroxylapatite column were incubated in cell-free transcription reactions with purified RNA polymerase (see Fig. 3) and $10 \mu \mathrm{l}$ of the Heparin-Sepharose fraction of aTFA. The synthesis of pre-tRNA was analyzed in an 8 percent polyacrylamide urea gel.

Lower panel: Analysis of hydroxylapatite fractions of aTFB by SDS PAGE and silver staining. The fractions eluted from the column are indicated on top of the lanes. The arrow indicates a $28-\mathrm{kD}$ a polypeptide whose intensity of silver staining was correlated with aTFB activity and therefore most likely is the transcription factor. A, fraction applied to the hydroxylapatite column; E。, RNA polymerase of E. coli, holoenzyme.

with deletions of 2, 4, 5 and 7 nucleotides of this sequence (Fig. 5). Additionally, the A residue at position 5 of the decamer was mutated to a $\mathrm{T}$ (plasmid pIC31/41). These constructs contained a mutated and an intact decameric sequence in tandem. If transcription continued through the first (mutated) terminator, transcription would terminate at the second (intact) decameric sequence and an elongated transcript would be synthesized. Therefore, the ratio of elongated to wildtype transcript depended on the efficiency of termination at both terminators and provided a means to quantitate terminator strength. In the experiments shown in Fig. 5, linearized DNA fragments were used as templates. RNA products caused by read through at the second terminator terminated at the end of the DNA fragments and were identified as run-off transcripts (Fig. 5). When transcripts from plasmid pIC31/36 containing two intact decameric sequences in tandem were analyzed, a strong signal corresponding to termination at the first decamer and a much weaker elongated transcript were observed (Fig. 5, lane 1). Analysis of pIC31/37 that lacks two T residues at the 3 '-end of the decamer revealed an almost reverse ratio (Fig. 5, lane 2), indicating that these $T$ residues have an important function in termination of transcription. Analysis of more truncated templates (pIC31/39-42) that lack 4, 5 and 7 nucleotides of the decameric sequence revealed that termination occurred almost exclusively at the second terminator (Fig. 5, lane 3, 4, 6). When the A residue at position 5 of the decameric sequence was replaced by a $\mathrm{T}(\mathrm{pIC} 31 / 41)$ only readthrough products were formed (Fig. 5, lane 5). This finding indicates that a cluster of five $T$ residues does not act as a signal to terminate transcription. These data corroborate the significance of this decameric sequence as terminator signal in Methanococcus.

To address the question as to whether internal DNA sequences also play a role in termination of transcription, the set of deletion mutants shown in Fig. 6 was constructed. These deletions were located in the DNA region

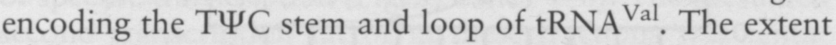
of the deletions is indicated in Fig. 6 by black bars below the genetic map of $\mathrm{tRNA}^{\mathrm{Val}}$. The linearized templates analyzed in Fig. 6 contained only a single copy of the decameric terminator sequence. Read through was detected by comparing the intensities of pre-tRNA and run-off transcripts. When the tRNA encoding region from position +89 to +93 (plasmid pIC31/4) was deleted, termination of transcription occurred with similar efficiency as at the wild-type template (Fig. 6, compare lane 1 and 2). After removal of 11 (pIC31/6) and 15 nucleotides (pIC31/5) located at positions +84 to +94 and +89 to +103 , respectively, the intensity of run-off transcripts was drastically increased and that of properly terminating transcripts decreased. This finding indicates that internal sequences contribute significantly to terminator function.

To investigate whether terminator sequences functional in Escherichia coli were also functional in the archaeal system, the DNA sequence downstream from position +104 of $\mathrm{tRNA}^{\mathrm{Val}}$ gene of $M$. vannielii was replaced by a DNA segment harboring the Rho-independent terminator of a tRNA ${ }^{\text {Phe }}$ gene of E. coli. Analysis of transcripts from this template (pIC31/23) revealed that termination of transcription at this terminator occurred with similar efficiency as at the homologous terminator of $\mathrm{RNNA}^{\mathrm{Val}}$ gene (compare intensities of RNA bands in Fig. 7). This finding indicates that an E. coli terminator sequence can direct termination of transcription in a methanogen.

\section{Discussion}

The first RNA polymerase from an archaeon was purified in the late seventies (Zillig et al., 1978). This enzyme from Halobacterium and RNA polymerases isolated from several genera of archaea (Prangishvilli et al., 1982; Thomm et al., 1985) were unable to transcribe homologous templates specifically in vitro. Thus, factors necessary for promoter recognition appeared to have been separated from the RNA polymerase during purification. However, until very recently no data were available providing direct 
evidence for the existence of archaeal transcription factors. The set-up of cell-free transcription systems made it possible to identify factors required for correct transcription. Thus far, one transcription factor has been detected in the methanogen Methanococcus (Frey et al., 1990) and the thermoacidophile Sulfolobus (Hüdepohl et al., 1990). The factors from both organisms were separated from the RNA polymerase by a simple fractionation of a crude ex-

\begin{abstract}
PIC 31/36 -ITTAATTTTGAGCTCCGAATCCGGCTGGGTCCACTATITTAATTT- $\frac{\text { Pvu II }}{+270}$
PIC 31/37 - IITIAATT GAGCTCCGAATCCGGCTGGGTCCACTATITIAATIT- $+\frac{1}{+268}$ PIC 31/39-IITTAA GAGCTCCGAATCCGGCTGGGTCCACTATTITAATIT- $+\frac{1}{+266}$ PIC 31/40 - IITTA GAGCTCCGAATCCGGCTGGGTCCACTATITTAATIT- $+\frac{1}{+265}$ PIC 31/41 - IIITा GAGCTCCGAATCCGGCTGGGTCCACTATITAATTI- $+\frac{1}{+265}$ PIC 31/42 - IIT GAGCTCCGAATCCGGCTGGGTCCACTATITAATIT- $+\frac{1}{+263}$
\end{abstract}

pIC $31 /$ *
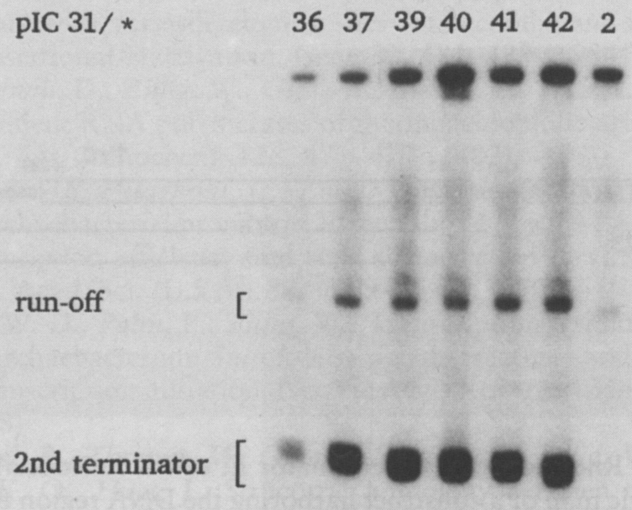

1st terminator

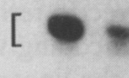

$\begin{array}{lllllll}1 & 2 & 3 & 4 & 5 & 6 & 7\end{array}$

Fig. 5. Analysis of effects of DNA deletions in the $3^{\prime}$ - flanking region of tRNA ${ }^{\mathrm{Val}}$ gene of $M$. vannielii on termination of transcription. A, DNA sequences of constructs containing the putative terminator signal TTTTATTTT in tandem. This decameric sequence that was deleted from the $3^{\prime}$-end as indicated in the Figure is boxed. The length of run-off transcripts caused by read through of the RNA polymerase at both terminators is indicated to the right. B, Analysis of transcripts from linearized DNA deletion clones shown in A; 1 st and 2 nd terminator indicates tRNA products terminating at the wild-type and second terminator, respectively. Note that at all clones with deletions of the decameric sequence (pIC31/37-pIC31/42) considerable read through at the second terminator occurred. Lane 7 shows an analysis of transcripts from linearized wild-type $\mathrm{tRNA}^{\mathrm{Val}}$ gene. Here, the efficiency of termination can be estimated by quantitation of the ratio of pre-tRNA to run-off transcripts.
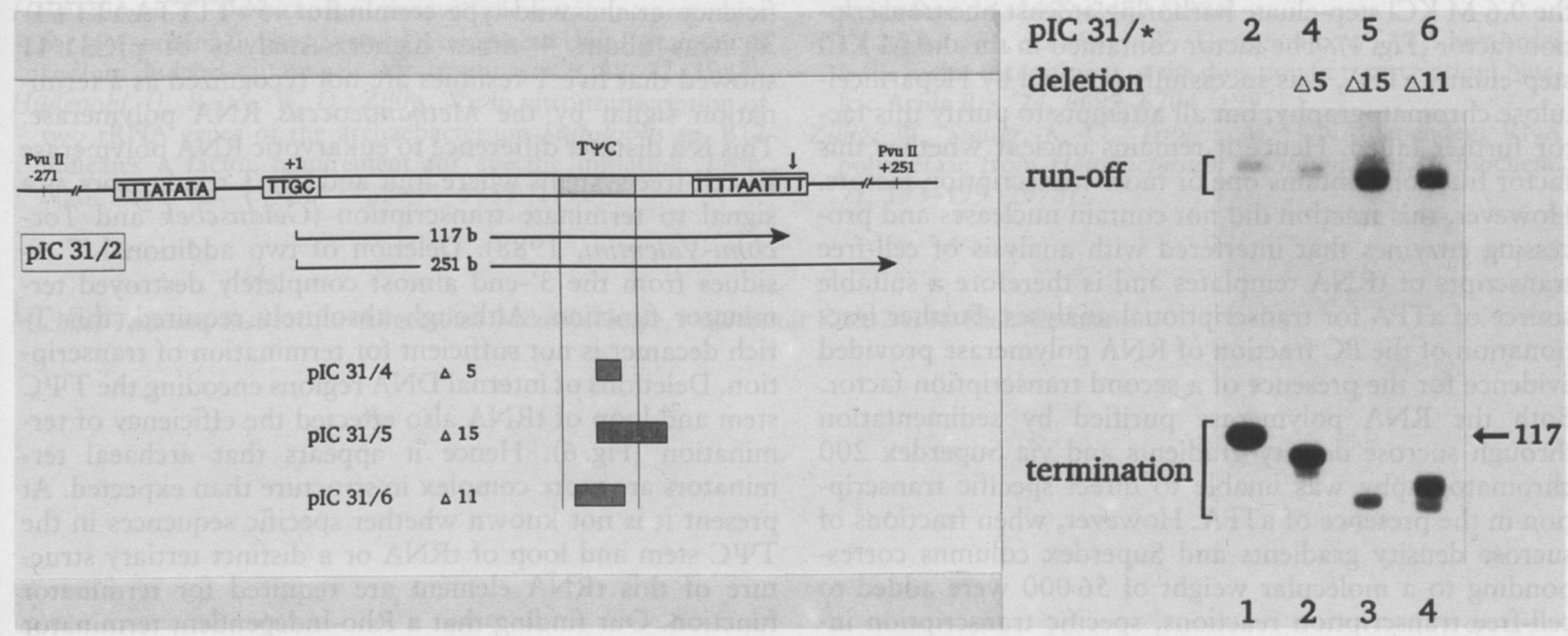

Fig. 6. Effects of internal deletions on terminator function A, genetic map of the gene encoding tRNA ${ }^{\mathrm{Val}}$; the TATA box, the

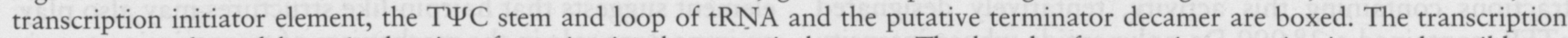
start site is indicated by +1 , the site of termination by a vertical arrow. The length of transcripts terminating at the wild-type termination site and at the end of template DNA linearized with PvuII are indicated below the Figure. The extent of DNA deletions in the region encoding the TUC stem and loop of tRNA are shown below.

$\mathrm{B}$, Analysis of transcripts from DNA deletion clones shown in A. 


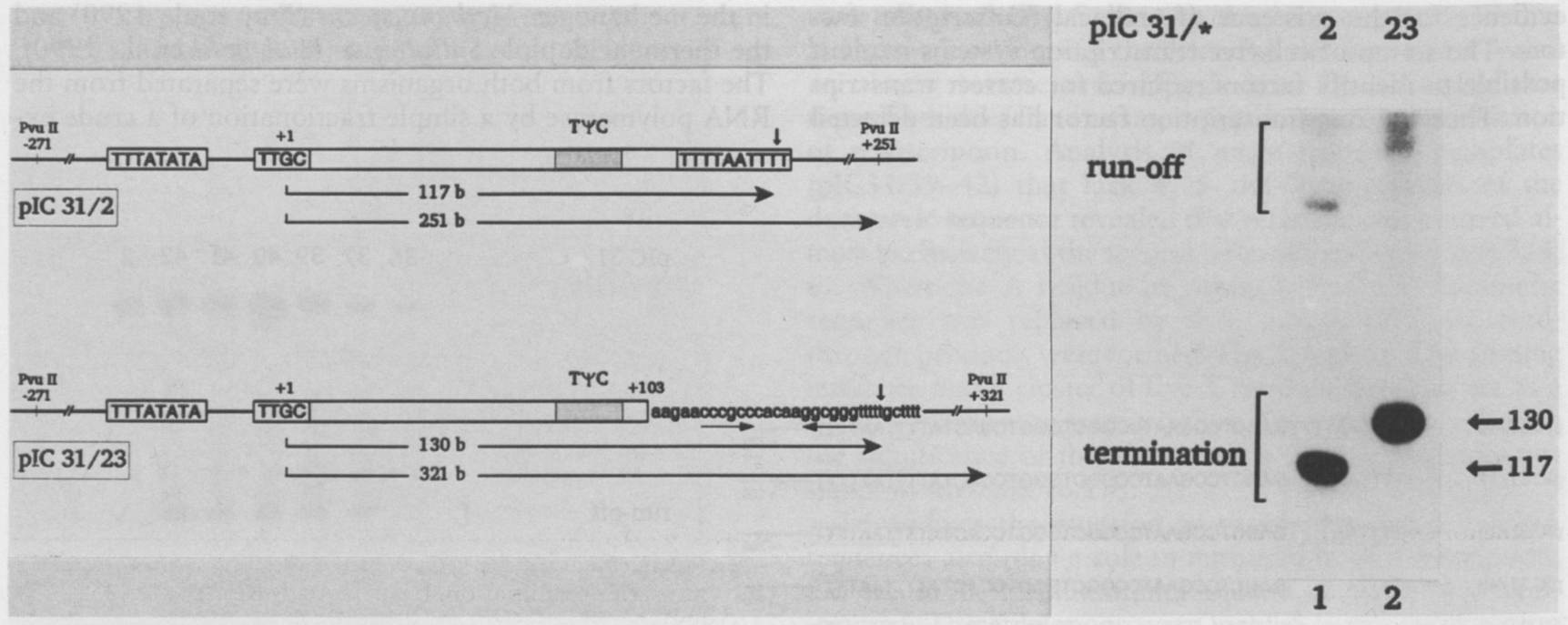

Fig. 7. A Rho-independent terminator E. coli is functional in the archaeal cell-free transcription system.

A, Genetic map of a construct harboring the DNA region encoding tRNA ${ }^{\mathrm{Val}}$ of $M$. vannielii and the terminator of a tRNA ${ }^{\text {Phe }}$ of E. coli (pIC31/23); the length of correctly terminating transcripts and of run-off transcripts from this template is indicated below. For comparison, the DNA region encoding wild-type $\mathrm{tRNA}^{\mathrm{Val}}$ (pIC31/2) is shown in addition.

$\mathrm{B}$, analysis of transcripts from the linearized templates shown in A.

tract $(\mathrm{S}-100)$. These factor preparations were very poorly defined and could contain more than one components.

In order to understand the process of assembly of components of the transcriptional machinery and promoter activation in archaea, it is necessary to identify and purify all transcription factors. Therefore, we tried to purify transcription factors from the two components of the reconstituted Methanococcus cell-free system, the $0.35 \mathrm{M}$ $\mathrm{KCl} \mathrm{PC}$ step-eluate containing the RNA polymerase and the $0.6 \mathrm{M} \mathrm{KCl}$ step-eluate harboring at least one transcription factor (Fig. 1). The factor contained in the $0.6 \mathrm{M} \mathrm{KCl}$ step-eluate, aTFA, was sucessfully purified by Heparincellulose chromatography, but all attempts to purify this factor further failed. Hence it remains unclear whether this factor fraction contains one or more transcription factors. However, this fraction did not contain nucleases and processing enzymes that interfered with analysis of cell-free transcripts of tRNA templates and is therefore a suitable source of aTFA for transcriptional analyses. Further fractionation of the PC fraction of RNA polymerase provided evidence for the presence of a second transcription factor. Both the RNA polymerase purified by sedimentation through sucrose density gradients and via Superdex 200 chromatography was unable to direct specific transcription in the presence of aTFA. However, when fractions of sucrose density gradients and Superdex columns corresponding to a molecular weight of 56000 were added to cell-free transcription reactions, specific transcription initiating at the promoter was restored. The most purified fractions containing this activity, tentatively designated aTFB, contained a 28000 Da polypeptide whose intensity in silver stained gels was correlated with factor activity (Fig. 4). The difference between molecular mass determined in denaturing gels and under native conditions sug- gested that aTFB is a dimer composed of two $28-\mathrm{kDa}$ polypeptides.

We have shown that Oligo-dT sequences detected at the 3 '-end of archaeal protein-encoding (Brown et al., 1989; Reiter et al., 1988) and stable RNA genes (Wich et al., 1986) actually are necessary for termination of transcription (Fig.5). The minimal sequence at the 3 '-end of tRNA ${ }^{\mathrm{Val}}$ gene required for termination of cell-free transcription was 5'-TTTTAATT-3'. However, termination efficiency at the wild-type terminator, $5^{\prime}$-TTTTAATTTT3', was about 4 times higher. Analysis of pIC31/41 showed that five $\mathrm{T}$ residues are not recognized as a termination signal by the Methanococcus RNA polymerase. This is a distinct difference to eukaryotic RNA polymerase III cell-free systems where four and five T residues act as a signal to terminate transcription (Geiduschek and Tocchini-Valentini, 1988). Deletion of two additional T residues from the 3 '-end almost completely destroyed terminator function. Although absolutely required, this Trich decamer is not sufficient for termination of transcription. Deletions of internal DNA regions encoding the TYC stem and loop of tRNA also effected the efficiency of termination (Fig. 6). Hence it appears that archaeal terminators are more complex in structure than expected. At present it is not known whether specific sequences in the TYC stem and loop of tRNA or a distinct tertiary structure of this tRNA element are required for terminator function. Our finding that a Rho-independent terminator of E. coli can perfectly replace the oligo-dT terminator element suggests that hairpin-like structures may also play an important role in the mechanism of transcription termination in archaea. A systematic mutational analysis of tRNA ${ }^{\text {Val }}$ structural elements will shed more light on the nature of archaeal terminators. 
Acknowledgment. We thank Dr. W. B. Whitman for comments on the manuscript. This work was supported by a grant from the Deutsche Forschungsgemeinschaft and the Fonds der Chemischen Industrie.

\section{References}

Brown, J. D., Daniels, C., Reeve, J. N.: Gene structure, organization and expression in archaebacteria. Crit. Rev. Microbiol. 16, 287-338 (1989)

Caillet, J., Plumbridge, J. A., Springer, M.: Evidence that pheV, a gene for tRNA ${ }^{\text {Phe }}$ of $E$. coli is transcribed from tandem promoters. Nucl. Acids Res. 13, 3699-3710 (1985)

Frey, G., Thomm, M., Brüdigam, B., Gohl, H. P., Hausner, W.: An archaebacterial cell-free transcription system. The expression of tRNA genes from Methanococcus vannielii is mediated by a transcription factor. Nucl. Acids Res. 18, 1361-1367 (1990)

Geiduschek, E. P., Tocchini-Valentini, G.: Transcription by RNA polymerase III. Ann. Rev. Biochem. 57, 873-914 (1988)

Gobl, H. P., Hausner, W., Thomm, M.: Cell-free transcription of the nifH1 gene of Methanococcus thermolithotrophicus indicates that promoters of archaeal nif genes share basic features with the methanogen consensus promoter. Mol. Gen. Genet. 231, 286-295 (1992)

Hausner, W., Frey, G., Thomm, M.: Control regions of an archaeal gene. A TATA box and an initiator element promote cell-free transcription of the tRNA ${ }^{\mathrm{Val}}$ gene of Methanococcus vannielii. J. Mol. Biol. 222, 495-508 (1991)

Hausner, W., Thomm, M.: Purification and characterization of a general transcription factor, aTFB, from the archaeon $\mathrm{Me}$ thanococcus thermolithotrophicus. J. Biol. Chem. 268, 24047-24052 (1993)

Heukeshoven, J., Dernick, R.: Improved silver staining procedure for fast staining in PhastSystemDevelopment Unit I. Staining of sodium dodecyl sulfate gels. Electrophoresis 9, 28-32 (1988)

Hüdepohl, U., Reiter, W. D., Zillig, W.: In vitro transcription of two rRNA genes of the archaebacterium Sulfolobus sp. B12 indicates a factor requirement for specific initiation. Proc. Natl. Acad. Sci. (U.S.A.) 87, 5851-5855 (1990)
Hüdepohl, U., Gropp, F., Horne, M., Zillig, W.: Heterologous in vitro transcription from two archaebacterial promoters. FEBS 285, 257-259 (1991)

Koller, G., Reeve, J. N., Frey, G., Thomm, M.: Transcription in vitro and in vivo of the 7S RNA gene associated with the ribosomal RNA operon in the hyperthermophilic archaeon Methanothermus fervidus. FEMS Lett. 98, 95-102 (1992)

Marsh, J. L., Erfle, M., Wykes, E. J.: The pIC plasmid and phage vectors with versatile cloning sites for recombinant selection by insertional inactivation. Gene 32, 481-489 (1984)

Prangishvili, D., Zillig, W., Gierl, A., Biesert, L., Holz, I.: DNAdependent RNA polymerases of thermoacidophilic archaebacteria. Eur. J. Biochem. 122, 471-477 (1982)

Reiter, W.-D., Hüdepohl, U., Zillig, W.: Mutational analysis of an archaebacterial promotor: Essential role of a TATA box for transcription efficiency and start-site selection in vitro. Proc. Natl. Acad. Sci. (U.S.A.) 87, 9509-9513 (1990)

Reiter, W. D., Palm, P., Zillig, W.: Transcription termination in the archaebacterium Sulfolobus: signal structures and linkage to transcription initiation. Nucleic Acids Res. 16, 12445-2459 (1988)

Schnabel, R., Thomm, M., Gerardy-Schahn, R., Zillig, W., Stetter, K. O., Huet, J.: Structural homology between different archaebacterial DNA-dependent RNA polymerases analyzed by immunological comparison of their components. EMBO J. 2, 751-755 (1983)

Thomm, M., Stetter, K. O.: Transcription in methanogens; evidence for specific in vitro transcription of the purified DNAdependent RNA polymerase of Methanococcus thermolithotrophicus. Eur. J. Biochem. 149, 345-351 (1985)

Thomm, M., Madon, J., Stetter, K. O.: DNA-dependent RNA polymerase of the three orders of methanogens. Biol. Chem. Hoppe-Seyler 367, 473-481 (1986)

Thomm, M., Sandman, K., Frey, G., Koller, G., Reeve, J. N.: Transcription in vivo and in vitro of the histone-encoding gene hmfB from the hyperthermophilic archaeon Methanothermus fervidus. J. Bacteriol. 174, 3508-3513 (1992)

Wich, G., Hummel, H., Jarsch, M., Bär, U., Böck, A.: Transcription signals for stable RNA genes in Methanococcus. Nucleic Acids Res. 14, 2459-2479 (1986)

Xu, L., Thali, M., Schaffner, W.: Upstream box/TATA box order is the major determinant of the direction of transcription. Nucleic Acids Res. 24, 6699-6704 (1992)

Zillig, W., Stetter, K. O., Tobien, M.: DNA-dependent RNA polymerase from Halobacterium halobium. Eur. J. Biochem. 91, 193-199 (1978) 


\title{
Structure and Function of the DNA-Dependent RNA Polymerase of Sulfolobus
}

\author{
MARTIN LANZENDÖRFER, DORIS LANGER, JOHANNES HAIN, HANS-PETER KLENK, \\ INGELORE HOLZ, IRENE ARNOLD-AMMER and WOLFRAM ZILLIG
}

Max-Planck-Institut für Biochemie, 82143 Martinsried, Germany

\begin{abstract}
Summary
The DNA-dependent RNA polymerase of the thermophilic archaeon Sulfolobus acidocaldarius (RNAP, EC 2.7.7.6) was shown to consist of thirteen components ranging in size from $122 \mathrm{kDa}$ to approximately 5 $\mathrm{kDa}$. They were named B, A', A", D, E, F, G, H, I, K, L, M and $\mathrm{N}$. The staining intensities indicate that they occur in an equimolar ratio. The complexity of the enzyme resembles that of eucaryal RNA polymerases. Most RNAP components and two subassemblies containing the components $\mathrm{D}$ plus $\mathrm{L}$ and $\mathrm{E}$ plus I could be separated in electrophoresis on a cellulose acetate support. The D-L subunit-complex exhibited a typical yellow colour with an absorbance maximum of $400 \mathrm{~nm}$. Inductive coupled plasma mass spectroscopy showed the absence of heavy metal atoms in this complex, but the presence of two zinc ions per RNAP molecule. The subunit $G$ is phosphorylated. The component $F$ was separated into five subspecies differing in charge density. By anion exchange chromatography an F-free RNAP and five variants, each containing a different $\mathrm{F}$-component $\left(\mathrm{F}_{5}\right.$ to $\left.\mathrm{F}_{1}\right)$ were separated. Renaturation of total dissociated RNAP led to an activity recovery of up to $30 \%$. On this basis experiments to reconstitute a functional enzyme from the separated subunits were done. The components $\mathrm{A}^{\prime \prime}, \mathrm{E}, \mathrm{H}$ and $\mathrm{K}$ appeared to be required for the basic activity of the RNAP. Crystallization of the RNAP yielded needle shaped and rhomboid crystals of a size of up to $0.5 \mathrm{~mm}$. Only F-containing RNAP could be crystallized, but no x-ray diffraction was obtained so far.

Genes encoding small subunits of the RNAP of S. acidocaldarius were compared to genes of small components of the eucaryal polymerases A (I), B (II) and C (III). Subunit K was shown to be homologous to the eucaryal component $A B C 23, N$ to $A B C 10 B$ and $L$ to $A C 19$. No homologies to bacterial subunits were found. The components $\mathrm{E}, \mathrm{F}$ and $\mathrm{G}$ have so far no bacterial or eucaryal counterparts. In contrast to the genes of the subunits $\mathrm{H}, \mathrm{B}, \mathrm{A}^{\prime}$ and $\mathrm{A}^{\prime \prime}$, which are transcribed jointly, the genes encoding the smaller subunits were transcribed separately. A further hint to a close relationship between archaeal and eucaryal transcription machinery was the discovery of a gene directly downstream of subunit L, which had a high similarity to the eucaryal transcription factor TFIIS.

In vitro transcription of the $16 \mathrm{~S} / 23 \mathrm{~S} \mathrm{rRNA}$-promoter of $S$. shibatae, the promoter of transcript 3 of the Sulfolobus virus SSV1 and of mutant derivatives with a cell-free extract or with purified RNAP of $S$. shibatae showed that the RNAP is able to recognize the correct start site by itself and independent of Box $\mathrm{A}$, whereas with a cell-free extract the start point of transcription was determined by the position of box $\mathrm{A}$. We conclude that one or more factors present in the cell-free extract are involved in box A directed transcription-initiation.
\end{abstract}

Key words: Sulfolobus - DNA-dependent RNA polymerase - Subunit composition - Reconstitution Crystallization - Genes encoding RNAP subunits - Transcription factor - Transcription analysis - Box A

\section{Introduction}

The complex process of transcription in the two domains Bacteria and Eucarya was subject of extensive research, but only little is known so far about the transcription machinery in the third domain Archaea (Woese et al.,

Abbreviations: RNAP = DNA-dependent RNA polymerase

1990). Archaea and bacteria contain only one type of DNA-dependent RNA polymerase (RNAP) synthesizing all RNA species, while eucarya contain three of them, each specialized in the synthesis of different RNA species. The subunit complexity of the RNAPs of archaea is very similar to that of the eucaryal enzymes (Zillig and Stetter, 